Aspectos da Administração Internacional

\title{
As Férias, as Diárias e 0 Regime Jurídico dos Servidores das Nações Unidas
}

A. FONSECA PIMENTEL

(Subchefe do Gabinete Civil da Presidência da República, Funcionário Internacional da ONU e da FAO de 1963 a 1969)

Em estudo anterior desta série de Aspectos da Administração Internacional, focalizamos o Sistema Comum de Salários, Vantagens e Outras Condições de Serviço das Nações Unidas, que vem a ser em última análise, mutatis mutandis, a nossa tão decantada e malograda paridade de vencimentos ou salários e demais vantagens financeiras, não só entre os três podêres da República, como também entre os próprios órgãos da administração. ${ }^{1}$

Hoje é nosso objetivo analisar sumàriamente neste artigo três aspectos da administração de pessoal das Nações Unidas que dão boa idéia de sua grande versatilidade.

São êles, respectivamente, as férias, as diárias e o regime jurídico prevalecentes para os servidores da organização internacional.

\section{O REGIME DAS FÉRIAS}

Como resultado do regime jurídico a que estão submetidos os servidores das Nações Unidas e que será objeto de estudo na Parte 3 dêste trabalho, há particularidades de férias no que concerne às várias categorias de servidores.

Normalmente, contudo, vigora para os servidores permanentes, inclusive os da categoria universitária (Professional Ca-

1. Publicado em plaquette pelo Centro de Documentação e Informática do DASP. 
tegory), que são os que nos interessam, em especial, aqui, o direito a dois dias e meio úteis de férias por mês. Isso dá ao servidor, no fim de um ano, direito a trinta dias úteis de férias, seja, seis semanas ou quarenta e dois dias corridos.

O que é digno de nota, porém, além do modo de computar o direito às férias, é a forma de sua fruição.

Em vez de ter, obrigatòriamente, como ocorre entre nós em virtude de dispositivo legal, de gozar as suas férias de uma só vez, o servidor das Nações Unidas pode fragmentá-las à vontade, de acôrdo com o seu interêsse, atendida, òbviamente, a conveniência da administração.

Assim, é-lhe facultado gozar quinze dias, uma semana, três dias, um dia e, até mesmo, meio-dia de férias, o que ocorre quando o servidor pretende deixar de comparecer ao serviço sòmente pela manhã ou pela tarde de uma jornada de trabalho. Isso é freqüente quando o servidor, por motivo de viagem de recreio, pretende "esticar" um pouco mais o fim-de-semana, seja no início, seja no fim.

A acumulação de férias é, outrossim, permitida em dois exercícios consecutivos, desde que o período acumulado, a se transferir para o terceiro exercício, não ultrapasse de sessenta dias.

Outra particularidade do regime de férias das Nações Unidas é a possibilidade, em casos excepcionais, de antecipação ou adiantamento de férias ao servidor que, havendo esgotado as regulamentares, necessita, por motivos justos ou razoáveis, a critério da administração, afastar-se do serviço em caráter particular. As férias antecipadas, que não poderão exceder de dez dias úteis, são também, não raro, utilizadas para prolongar as regulamentares, nos casos de afastamentos mais prolongados, para uma viagem de longa duração, por exemplo.

Finalmente, para concluir esta descrição sumária do regime de férias das Nações Unidas, o servidor que, ao ser dispensado, possui férias não gozadas, tem reconhecido o direito de recebêlas em dinheiro. Do mesmo modo, o servidor que, ao ser dispensado, dever férias antecipadas, indeniza-as à administração, mediante o competente desconto em seu último pagamento.

Como se vê, não se poderia desejar maior maleabilidade num regime de férias do que a que prevalece nas Nações Unidas.

É verdade que a sua computação e o seu contrôle exigem, evidentemente, maior trabalho por parte da administração e, em especial, de seus órgãos de pessoal. 
Mas, o sistema compensa, encarado tanto do ponto de vista do interêsse da organização como do ponto de vista do interêsse do servidor.

A êste assegura o sistema extrema flexibilidade e comodidade no gôzo das férias, de acôrdo com as suas conveniências particulares.

Por outro lado, a administração lucra no que concerne especialmente ao absenteísmo, porque muitas faltas e meias faltas que, no Brasil, devido à rigidez de nosso sistema de férias, são dadas ao serviço mediante atestados médicos graciosos ou de favor (lá de muito difícil obtenção), se poupam à organização mediante a adequada utilização de suas férias por parte do servidor.

\section{O REGIME DAS DIÁRIAS}

A mesma versatilidade que se observa no regime de férias existe também nas Nações Unidas em relação às diárias para afastamento a serviço da organização dos funcionários (daily subsistence allowance ou per diem, como são correntemente chamadas.)

Estas são rigorosamente calculadas para atender a três fatôres básicos ocorrentes no afastamento:

a) hospedagem ou pousada condigna, de acôrdo com a hierarquia ou status do servidor;

b) alimentação condigna, nas mesmas condições da alínea anterior;

c) outras despesas, tais como transporte (táxi, ônibus), carregador, gorjetas, etc.

Apesar disso e como resultado do fato de que os fatôres básicos acima indicados são aferidos com precisão, as diárias pagas pelas Nações Unidas no afastamento de seus servidores a serviço da organização se revelam bastante modestas quando comparadas com as que a administração brasileira paga a seus servidores que viajam em missão oficial ou de aperfeiçoamento para o exterior. (Sendo as Nações Unidas um complexo de organizações internacionais espalhadas por tôda a terra, os afastamentos de seus servidores a serviço ocorrem quase invariàvelmente para o exterior, salvo raras exceções). ${ }^{2}$

2. Para melhor conhecimento da estrutura e funcionamento da familia de organizações das Nações Unidas, veja-se o Cap. 2 de nosso livro recentemente publicado A Paz e o Pão (Desafio às Nações Unidas), Brasília 1970. 
A diária máxima, para altos dirigentes diretamente subordinados ao Secretário-Geral ou aos responsáveis supremos pelas chamadas agências especializadas, orça atualmente pela casa dos US $\$ 35.00$ ou US\$40.00. A um técnico de nível universitário paga-se a diária de aproximadamente US\$25.00. Isso no Brasil, à falta de uma regulamentação adequada da matéria, pela qual nos estamos propugnando, é diária, não raro, de bolsista.

Outra característica do regime de diárias das Nações Unidas é a sua variação em virtude da diferença do custo de vida entre os principais centros para os quais se afasta o servidor internacional a serviço da organização.

Assim, o montante da diária não só varia de um país para outro como também dentro de um mesmo país, de uma cidade para outra, se houver diferença apreciável no custo da vida. A diária do servidor internacional que se afasta em serviço para Buenos Aires ou Mar del Plata, na Argentina, é uma e para o restante do país, outra, inferior àquela. O mesmo ocorre, no Uruguai, no que concerne a Montevidéu e Punta del Este, de um lado, e o resto do país, de outro.

Mais do que isso ainda, a diária paga pelas Nações Unidas a seus servidores que se afastam em objeto de serviço pode variar, inclusive, em um mesmo local, em função da época do ano, principalmente nos centros de caráter turístico. Assim, a diária do servidor que se afasta em serviço para as Bahamas, centro turístico de nomeada internacional, é de US\$33.00 durante a estação turística (de 15 de dezembro a 15 de abril) e de US\$23.00 no restante do ano.

Ademais, após sessenta dias de permanência num mesmo local, o montante da diária sofre apreciável redução, partindose do pressuposto de que, por um período de afastamento por prazo superior, o servidor poderá fazer arranjos que reduzem o seu custo, ou, em outras palavras, que a permanência por uns poucos dias em determinada localidade resulta relativamente mais dispendiosa do que por um período mais prolongado.

Como se vê, no que diz respeito ao regime das diárias, as Nações Unidas atingiram um grau de refinamento que estamos ainda longe de alcançar, com o nosso sistema, principalmente no que toca aos afastamentos para o exterior, de diárias por demais generosas e sem correlação plausível com os efetivos custos dos deslocamentos.

A essa situação, conforme nós estamos propugnando, é que se impõe pôr côbro, com urgência, em benefício da maior 
austeridade e eficiência da administração, pois esta, ao contrário do que supõe muito administrador menos avisado, não se obtém, em caráter generalizado e a longo prazo, à custa da concessão de vantagens excessivas a determinados grupos em detrimento do todo.

3. REGIME JURIDICO

Para disciplinar as relações entre a administração e o pessoal (staff), existem bàsicamente nas Nações Unidas três textos ou documentos:

1) Os preceitos básicos de pessoal (Staff Regulations), que desempenham, mutatis mutandis, e de maneira mais detalhada, o papel do título da Constituição que, entre nós, dispõe sôbre os funcionários.

2) As regras de pessoal (Staff Rules), que, pela mesma forma, correspondem mais ou menos ao nosso Estatuto dos Funcionários.

3) O Manual (Manual), que regulamenta, pormenorizadamente, as Staff Regulations e as Staff Rules e equivale à nossa regulamentação Estatuto.

O regime jurídico do pessoal a serviço das Nações Unidas é, assim, aparentemente um.

Ocorre, porém, que as Staff Regulations e as Staff Rules fazem as seguintes distinções entre o pessoal, com implicações sôbre os seus direitos e deveres:

I - Quanto à natureza da função:

1) permanentes;

2) temporárias.

II - Quanto à duração do cargo:

1) permanentes;

2) indefinidos;

3) de prazo fixo (fixed-term), os quais, por sua vez, subdividem-se em de prazo longo (long-term), se passa de dois anos, de prazo médio (mid-term), se é entre um e dois anos, e de prazo curto (short-term), quando é por menos de um ano.

III - Quanto à forma de recrutamento:

1) internacionais;

2) locais.

De acôrdo com a sua localização em cada um dêsses grupos, terá o servidor mais ou menos direitos, aplicando-se-lhe ou não determinadas partes da legislação. 
É óbvio, porém, que os funcionários que gozam de maior estabilidade e mais amplos direitos (entitlements) são os permanentes de recrutamento internacional (que formam bàsicamente a chamada Professional Category), seguidos dos permanentes de recrutamento local (que constituem a General Service Category). ${ }^{3}$

Os primeiros, além de gozarem de todos os direitos e regalias constantes das Regulations e Rules, dispõem de uma escala de salários fixados em dólares e desfrutam de status quase diplomático e, em alguns casos, plenamente diplomático, aplicando-se-lhes a Convenção de Privilégios e Imunidades que as Nações Unidas celebram com os seus Estados-membros. Em conseqüência, estão, via de regra, isentos do pagamento de impôsto de importação e de renda, de prisão por ato praticado em virtude do exercício do cargo etc. Dentre os servidores de status provisório, contam-se, entre outros:

a) o chamado pessoal de projeto (project personnel), ou seja, servidores contratados para prestarem colaboração na sua especialidade em determinado projeto, tendo os seus respectivos cargos a duração improrrogável dêste (usualmente de dois a cinco anos);

b) os especialistas do tipo consultor ou assessor, geralmente contratados para determinada tarefa, principalmente de estudo ou pesquisa, a curto prazo, ou seja, em têrmos de meses (short-term).

Esse pessoal desfruta de menos direitos e regalias por não se lhe aplicarem determinadas partes ou disposições das Regulations e das Rules.

Assim, ainda que sob a aparência de um só regime jurídico, em face da existência de um corpo unificado de normas a respeito, há nas Nações Unidas, em verdade, diversidade de regimes jurídicos, os quais, aplicados criteriosamente e da maneira flexível e prática indicada, facilitam as relações da organização com os seus servidores, sem suscitar atritos ou criar problemas.

Aí estão, expostos muito sucintamente, três aspectos da administração de pessoal das Nações Unidas, que revelam, de maneira clara, o seu alto grau de flexibilidade e versatilidade, em benefício da maior eficiência da organização.

3. Em algumas circunstâncias, surje também a categoria dos chamados semi-locais (ou seja, servidores recrutados internacionalmente para postos de natureza local, por falta de gente habilitada no mercado local de trabalho), os quais desfrutam de alguns dos direitos e regalias dos funcionários internacionais. 